\title{
ELECTIVES SUBJECTS IN ZIMBABWEAN HIGH SCHOOLS: EXAMINING INFLUENTIAL ATTRIBUTES FOR PROSPECTIVE STUDENTS FOR HOME ECONOMICS AND PHYSICAL EDUCATION IN MASVINGO
}

\author{
Lilian Manwa ${ }^{1 *}$, Jenet Mudekunye ${ }^{2}$, Molyn Mpofu ${ }^{3}$, Lokadhia Manwa ${ }^{4}$ \\ $* 1,4$ Senior Lecturers, ${ }^{2}$ Lecturer at Great Zimbabwe University in the School of Education \\ ${ }^{3}$ Lecturer, University of Eswatini,Departmentof Consumer Science Education and Community Development
}

*Corresponding Author: -

\begin{abstract}
: -
This interpretive inquiry sought to establish the factors that influence selection of Home Economics (H.E) and Physical Education (P.E) as elective subjects (electives) in Zimbabwean High Schools. The study employed a descriptive case study research design. A sample of forty (40) participants comprising twenty-four students and sixteen teachers was randomly selected from four (4) schools in Masvingo district. In-depth face-to-face interviews and focus group discussions were used to collect data. The major finding of the study was the failure by government and stakeholders to adequately fund H.E. and P.E. electives, consequently making the subject more expensive for the parents hence, discouraging students from selecting the subjects. Lack of funding exposes schools to inadequate facilities leaving the schools resorting to theoretical instruction. The study recommends that resource provisions for electives be improved in order to minimise practical fees and attract takers for the elective subjects.
\end{abstract}

Keywords: Electives, practical subjects, home economics, physical education, prospective 


\section{INTRODUCTION}

The Zimbabwean high school curriculum comprises of many subjects such that most high schools offer 8-13 subjects. These subjects are divided into two categories, the core (compulsory) and the electives (those to choose from).This scenario results in school administrators choosing subjects from the wide curriculum to implement at school level. The Zimbabwe education policy on subject selection encourages students to take up all the core subjects; Mathematics, English, Shona/Ndebele (or any native language), Science and at least one practical subject. Although practical subjects are considered to be important, from the ten practical subjects, each school is expected to select a few electives of its own choice which it may consider important or less expensive to run since it is not feasible to offer all of them at the same time. Students are also expected to choose at least one subject from the practical subjects offered at the school.

Movchan and Zarishniak (2017) opine that, in Ukraine, high school subjects are traditionally divided into compulsory and optional subjects. This means that subject selection is not unique to Zimbabwe educational systems but across the globe. The curriculum is very broad in order to take care of the diversified world of work and also to cater for human needs and wants. The focus of this study is on Home Economics (H.E) and Physical Education (P.E) since these electives have received little attention by researchers. Therefore, this study is intended to add knowledge to the scanty literature on practical subjects particularly H.E and P.E.

Practical subjects in Zimbabwe are generically offered in two categories, those for males and females. Woodwork, Metalwork and Building are male dominated while H.E subjects namely Fashion and Fabrics, Food and Nutrition and Home Management are for girls. Physical Education and Agriculture were inherently for both sexes although they seem to be dominated by males. This complex process has been a thorn in the flesh for both students and teachers of electives especially practical subject specialists. Lutz (2018) states that before students even reach senior year, there is a lot of pressure to choose a career path or select subjects and have everything planned out by the time they graduate high school. Lutz (2018) further express that from the experiences of most people, this is oftentimes much easier said than done to make such crucial decisions at that tender age as a handful of people over the age of fifty (50) are still trying to figure out what they want to do when they grow up. However, scholars such as WolpertGawron (2018) andSamara (2015) argue that subject choice among high school students represents an important decision and challenge that can play a large role in preparing students for college and career choices and as choosing electives reflects the same process that they will see again at college, hence representing an important decision that influences an individual's career life. Wolpert-Gawron (2018) expresses that the very qualitystudent choice-seems to be one of the factors that make electives vulnerable. Teachers may face the risk that is linked to the number of subject takers where in some cases very few or no subject takers may be experienced.

Movchan and Zarishniak (2017) assert that students can be misled by the variety of appealing subjects and ignore the more complicated ones that are less interesting in their opinion. Similarly, Daly and Last (2017) aver that the primary factor motivating choice of subjects was workload, with students preferring less demanding electives. This implies that there are so many variables that need to be considered when students are choosing electives. Babad (2001) stipulates that subjects are in most cases selected for their prospective intellectual level, expected quality of teaching, students' potential learning, occupational gains and because they are comfortable and easy. In the same vein, the study by Altunbay (2018) points out what determines subject preferences of the students was the content of the course andthe subject teacher attributes. This implies that the performance of the subject teacher is an importantissue which is considered by students when choosing electives.

Teachers on the other hand are anxious of whether they find enough subject takers and also concerned about the quality of prospective students. Students in most cases pay attention to their actual interests, and select the most fundamental knowledge and skills which provide lifelong benefits to them (Yu \&Mocan, 2018). This may imply that such students may disregard all other inhibiting factors and pursue their dreams. Ting and Lee (2012) assert that the perceived difficulty, perceived interest and future career skills may be a primary reason for the choice of the elective but for other students they may be most concerned about the perceived difficulty of the elective and will avoid enrolling in such an elective. On the other hand students who are not focused may count the cost but disregard the lifelong benefits.

In Zimbabwe, most high school students are still at adolescent stage (12-18) andmay find it difficult to make sound decisions concerning the choice of electives (H.E and P.E).Therefore, parental involvement may be required in order to channel their children along careers of their choice, disregarding the child's ambitions. Wolpert-Gawron (2018) confirms that students need to be more connected to adults (parents and community) who are well informed about the importance of the electives for them to make right choices. Adults as advisors may face challenges from peers of high school learners who may also want to influence their choices. Many a times, electives reflect the interests of the teachers that teach them as well as the students that choose them (Babad, 2001). This may permit students to automatically have a self-selected connection to the connected adult.

The selection of electives in most Zimbabwean high schools is an ongoing process that usually begins from form two (2). Some high schools give their students another chance at level three (Form 3) to choose subjects they link with career prospects. There are many variables taken into account by students choosing electives. These are the status of the subject in society (how it is rated by people), career prospects, degree of difficulty of the subject, expenses involved as well as teacher quality. Altunbay (2018) affirms that variables that may be considered as influential in the choice of electives include subject schedule, teachers, friends, impact of the person who had the subject before, relationship with the teachers in everyday life, teacher's teaching style, homework and projects within the subject. All these variables are a web of complicated issues which also involve parents and finances.

According to OECD (2019) and Wolpert-Gawron (2018), for many schools, budget cuts and an ebb and flow of educational funding are par for the subject. This implies that electives may be given less funding as compared to core 
subjects. In Zimbabwe, practical subjects suffer most in terms of finance as they are naturally expensive to run. In Zimbabwe, the demand for STEM (S.T.E.M. is an acronym for Science, Technology, Engineering and Mathematics) jobs increased more than double over the past years but the input of students who do STEM subjects were also dwindling. This scenario prompted the government of Zimbabwe to embark on rigorous campaigns which were meant to attract more STEM students at the expense of electives.

Practical subjects on the other hand lack such support as they are not considered to be core subjects. Technical and vocational training was the focus for many developing countries as a means to eradicate poverty. Most governments in Africa emphasise on practical subjects as they intend to impart life skills for self-sustainance but the level of support they give to practical subjects is mostly disheartening to teachers. Harirforoosh and Stewart (2016)state that the potential drawback is that practical activities require sufficient faculty time, adequate resources and appropriate faculty expertise. Based on the background highlighted, this study sought to examine the attributes which influence prospective students for Physical Education and Home Economics (electives) in Masvingo. The following objectives guided this research intended to find out factors that determine selection of H.E and P.E (electives) by students and to establish factors that impact on electives in Zimbabwean high schools.

\section{Methodology}

This study used the qualitative theory and a descriptive case study design to gather data from the participants. The descriptive design was suitable for this research because it enabled the researchers to collect rich data from the point of view of participants. Descriptive inquiries based on a qualitative paradigm are best when studying issues that affect the emotions and feelings of humans (Denzin \& Lincoln, 2018; Salkind, 2017; Harirforoosh \& Stewart, 2016; Gray, 2011), which is the major issue in this study

A sample of forty (40) participants was drawn from a population of four hundred students and twenty (24) teachers from four (4) schools. Stratified random sampling was used to select participants, teachers, students and subjects (H.E and P.E) were used as strata. The sample consisted of sixteen (16) teachers and twenty four (24) students who were involved in the choice of electives. Four (4) teachers and (6) students were from each of the four (4) schools. Stratified random sampling technique is appropriate when choosing participants with diversified backgrounds (Salkind, 2017; Cresswell, 2012; Cohen, Manion\& Morrison, 2011).

The qualitative descriptive case study consisted of in-depth face-to-face interviews with sixteen (16) teachers and four (4) focus group discussions which consisted of six (6) students from each of the four (4) schools. Salkind (2017) and Gray (2011) posit that the use of two or more instruments allows triangulation of data which enhances the credibility of the results of the study.

Participants were willing to provide rich data in a friendly manner. According toGuion, Diehl and McDonald (2012) it is critical in research to seek consent from participants and also to observe ethical practices. Data from both instruments was recorded using smart phones and non verbal ques were captured on interview schedules. Data was transcribed and coded in line with research objectives.

Qualitative data from in-depth interviews and focus group discussions were coded into themes and sub-themes through coding and condensing the codes to reflect the objectives. Data from the two (2) instruments were presented on a table and underwent thematic analysis.

\section{Data presentation and discussion}

Factors that determine selection of H.E and P.E (electives) by teachers and students

Table 1 Factors that determine selection of H.E and P.E (electives)

\begin{tabular}{|l|l|l|}
\hline Factors that determine selection of HE and PE & Number of teachers & $\begin{array}{l}\text { Number } \\
\text { students }\end{array}$ \\
\hline Level of education of parents & 16 & 14 \\
\hline Community projects & 10 & 16 \\
\hline Peer pressure & 15 & 12 \\
\hline Teacher competence & 8 & 10 \\
\hline Resource provision/ sponsorship & 16 & 20 \\
\hline Subject demands & 12 & 18 \\
\hline Perceptions of students towards the subject & 14 & 13 \\
\hline
\end{tabular}

Table. 1.shows factors that negatively influenced the selection of H.E and P.E (electives) by learners in Zimbabwean high schools. Sixteen (16) teachers and fourteen (14) students revealed that the level of education of parents was a determinant factor. Ten (10) teachers and sixteen (16) students indicated that community projects were also influential factors. Peer pressure was mentioned as a negative factor by fifteen (15) teachers and twelve (12) students. Eight (8) teachers and ten (10) students revealed that teacher competence was another contributory factor. All teachers and twenty (20) students pointed out that resource provision and sponsorship were guiding factors on practical subjects selection. On the issue of subject demands, fifteen (15)teachers and eighteen (18) students stipulated that practical subjects were rather 
too demanding while fourteen (14) teachers and thirteen (13) students indicated that they had negative attitude towards the two practical subjects (H.E and P.E).

This study revealed that parents' level of education negatively influenced learners' selection of electives (H.E and P.E) in Zimbabwean high schools. Most participants indicated that parents play a pivotal role in guiding learners on electives they choose. Samara (2015) reiterates that parents may be regarded as their children's first counselors. One student participant revealed that his father advised him to take his career paths. This implies that most children consider their parents as significant others and role models. Children at adolescent stage require family support when making decisions since adolescents is a challenging stage fully of confusion. Some students indicated that their parents had low level of education and were not well informed on the importance of different practical subjects. Manwa (2014) asserts that uneducated parents may lack important information on career choices and electives. Mudekunye (2019) also affirms that students from parents with knowledge about the subject may assist the student to make right choices. Parents, siblings and other family members may have more influence than most agents of socialization but influence from peers cannot be underestimated. Almost all teachers and quite a number of students agreed that peer pressure somehow influenced choices of electives. Moat high school students have a tendency of conforming to demands of their peers as they may want their approval and acceptance.

Most participants especially teachers revealed that community projects had an influence on subject choice especially those which generate income such as farming projects. One teacher cited that agriculture as a subject attracts students from families who are surviving on commercial farming. The government of Zimbabwe is agro based hence, the emphasis of agriculture which also disadvantages other electives. Kapungu, (2007) and Mavhunga (2009) confirm that the education system of Zimbabwe was shaped and transformed by the agro based economy. One participant pointed out that the government has shown its full support by establishing vocational training centres offering agriculture in all provinces which is not the same with other electives. This scenario encourages parents to send their children to such facilities as they are more relevant and cheaper to fund. Practical subjects in this regard are considered as a knowledge support system which enhances the teaching and learning of skills for survival.

Most participants indicated that since the prospective students had no experiences related to the competence of teachers for electives the aspect of how effective teachers are, may not be of much relevance. However, information about teacher competence is not sacred but is for public consumption since students discuss such issues publicly. One H.E student respondent highlighted that the main reason she chose the subject was that almost all students who undertook the subjects did well and in most cases with very good passes. Another PE student echoed similar sentiments that high school subjects pass rate attracts subject takers for electives. High pass rate for practical subjects is in most cases the effort of the teacher which stimulates the students to work extra ordinarily hard (Sweeney, 2012; Tope, 2012; Cubukcu, 2010). The few participants who considered teacher competence as a factor revealed that the pass rate record of the electives usually reflects back on teacher competence. High pass rate or failure record of HE and PE is a product of both the teacher and student effort coupled with the availability of resources.

On the issue of resource provision and sponsorship, the study established that almost all participants accepted that without resources it was very difficult to choose an elective that was not well funded since results were compromised. Thus, practical subjects are generally expensive to run and require concerted effort from all stake holders to adequately supply materials required. The prevailing ailing Zimbabwe economy has worsened the situation in schools as the government is failing to educate its citizens (OECD, 2019; Smith, 2018; Cram \&Docampo, 2016). Mudekunye, Manwa and Manwa (2012) confirm that the government has placed the whole burden of educating students on parents. Parents are faced with a myriad of challenges caused by severe economic crisis in Zimbabwe. One female student indicated that the funding of her education greatly caused anxiety and stress to the whole family.

The current study revealed that teachers experienced challenges of students who failed to cope with subject demands. It is common knowledge that skill training is quite involving since both teachers and students are expected to refine their skills by repeating the same thing over and over again. The process of skill acquisition requires commitment and it is also time consuming. According to Daly and Last (2017)students may be reluctant to take more challenging electives despite having an interest in the subject and the implication is that their consideration may negatively influence choices for future programmes. Most students submitted that learning how to use different types of hi-tech machinery, equipment and tools at the same time expected to produce examinable products is a mammoth task for the average student. Thus, the amount of time and effort required to produce good passes for the elective influenced the attitude of prospective practical subject takers. Wolpert-Gawron (2018) and Marzano (2009) affirm that subject choices have always been linked to career choice which may increase student effort, task performance, and subsequent learning.

Most participants revealed that the major determinant of students' attitude towards practical subjects is how it is rated among other core subjects and electives. Practical subjects have a history of being labelled subjects for the less gifted and of low status. Harirforoosh and Stewart (2016) aver that the status of the subject as elective is also taken into consideration by prospective students. In Zimbabwe the mentality that was instilled to people that the F1 system of education (academic orientation) was for the gifted and F2 system (practically oriented) was for the less gifted. The mentality was continuously transmitted from generation to generations and most people associate practical subjects with blue collar jobs which are less paying.

Ambitions of students as they choose subjects are to meet their needs and wants in life without much struggling. High paying jobs such as those in engineering and medicine are very inspiring to the extent that most young people find themselves in other fields after they have failed to become pilots, doctors and engineers. This implies that choosing an elective which results in low salary is not considered the best option. Negative attitudes were mentioned by most students as inherently from the future prospects of each elective. Most high schools prefer to offer Fashion and Fabrics as it is 
considered to be cheaper than Food and Nutrition and Home Management. Students who prefer to pursue the food industry may face an attitudinal problem towards Fashion and Fabrics since they do not intend to get into the clothing industry. It was found out in the study by Altunbay (2018) that the most important factor determining the preferences of the students on the selection of electives was the content of the subject which was used as way to meet the career for a specific career. One Home Economics teacher suggested that offering all

H.E subjects was the solution but most schools do not afford to manage them all at the same time. Time tabling and space for other practical subjects in the school curriculum such as P.E was seen as another challenge for all electives.

\section{Factors that impact on electives in Zimbabwean high schools}

This study revealed that both H.E and P.E subjects were facing problems of limited number of subject takers. One teacher pointed out that at their school they were struggling to convince students to select subjects they teach since other electives such Religious Studies, Computer Science, Woodwork and Agriculture compete for the same students. Results from the schools indicated that the numbers of subject takers for H.E and P.E mostly ranged from two (2) to fifteen (15) students per class out of about fifty to sixty students in a class. Home management was cited by H.E teachers as a subject that is failing to get takers and most schools are no longer offering the subject. One of those H.E teachers lamented that Home management is one of the most important subjects which is linked to personal hygiene and home care but was being shunned by most students. Manwa, Mahundiand Manwa (2018) affirm that most students and school administrators lack the knowledge of the importance ofHome Management to the family.

The criterion which is followed by different school administrations on selecting electives was a thorn in the flesh for most teachers. Results from this study are similar to those from the study by Daly \& Last (2017) which revealed that participants indicated that elective grading and selection criteria had a significant impact on their choices. Teachers from the four schools expressed their concern over the idea of allocating classes based on merit. All the four schools were allocating difficult subjects such as physics and chemistry to the gifted and leave the simple electives such H.E and P.E to the other classes. The teachers who were given the weak students were complaining that the results were compromised because of grouping students according to giftedness. This may imply that school heads are using the strategy of grouping/segregation. This strategy involves the separation of gifted and less gifted when they are allocated classes. Most teachers mentioned that children were being isolated to learn on their own basing on their mental capabilities. The gifted were the most affected as they were supposed to learn away from average and lower performing counterparts. This is done to allow gifted children to compete on their own, rather than leaving them in mixed classes.

From the four schools, two schools gave class names which had a meaning such as form 4 east meaning that students in that class were like the wise men from the east and the other school was using letters of the alphabet such as form $4 \mathrm{~A}$ meaning that students in that class were the cream of the school while those in form 4D were the least gifted. Some teachers mentioned that it is easier for the practical subject teacher to teach learners of similar capabilities. It can also be referred to as the pull-out program because gifted learners are pulled out of their regular classrooms to participate in more complicated subjects [EPSD 2018; IEA 2014; Special Education Support Services (SESS) 2013].

The current study discovered that most teachers blamed the Zimbabwean policy on the selection of electives at high school level which gives students and parents the latitude to choose the electives they want. They also submitted that the schools are also given the chances to choose the strategies they may use that are based on their school policies. One school from the four schools involved in this study used a different strategy in the allocation of electives where students were expected to pursue the elective in a class allocated by administration. The other three schools were placed in one block of four or more electives on the time table and then the administration would allow students to select what they intend to study. The general view from both H.E and P.E teachers was that the process of selecting electives by students was rather confusing and stressful and also time consuming.

This study also revealed that H.E and P.E as subjects which needed to be selected by students were experiencing attitudinal problems from students, school administrators, parents and community. Teaching of H.E and P.E requires the input of the student, family and school administrators to have the output which is reasonable in terms of pass rate. Thus, negative attitudes from aforementioned stake holders became a hindrance in acquiring subject takers. Most teachers and students revealed that support from parents in terms of resource provision is pivotal in the teaching and learning of the subjects. These results are in line with Mudekunye and Sithole (2012) that parental support is always linked to motivation and positive performance of students. Motivating students usually encourage them to pursue electives which may result in enhancing retention of subject takers.

The results pertaining to attitudes of school administrators on the selection of electives indicated that the majority of the school heads had negative opinions towards H.E and P.E basing their perceptions on the expenses required to implement the subjects. Most of the teachers revealed that school heads complained that H.E and P.E were both resource consuming in terms of teaching materials, finance as well as time which is difficult to recover. One Food and Nutrition teacher mentioned that her school head had a tendency of critically scrutinizing my orders and this was very discouraging especially when the orders were reduced and became insufficient. When subjects are under resourced students may end up dropping the electives. Manwa, Mahundiand Manwa (2018) assert that negative attitudes of administrators towards practical subjects are very retrogressive and counterproductive. On the other hand negative attitudes of subject teachers were cited as another cause of subject dropouts in electives (H.E and P.E). However, in most cases, when teachers have positive attitudes towards electives they stand their ground to promote the subject in every way. This may result in very few subject drop outs.

Findings of this study also revealed that the education system in Zimbabwe is generally not sponsored by the government. This has constantly affected the teaching and learning of H.E, P.E and other practical subjects. Most of the participants 
in this study affirmed that students were not keen to study underfunded electives without appropriate resources to use during lessons. Manwa (2019) and Mudekunye et al, (2012) confirm that most parents struggle to fund the education of their children to the extent that some may not manage to register the number of subjects required for a full certificate in Zimbabwe high schools. The Zimbabwe school examination board requires a candidate to have a minimum of 5 Ordinary level subjects for entry to tertiary level. This implies that if the student fails to register 5 subjects he/she may end up having an incomplete certificate which does not qualify the student to advance to tertiary level. Most H.E teachers mentioned that some Fashion and Fabrics students failed to secure fabrics for examination garments as a result they did not write the final examinations. This resulted in increased subject drop outs for electives (H.E and P.E) in Zimbabwean high schools.

\section{Conclusions and recommendations}

Conclusions drawn from this study are that students, teachers and parents all face various challenges during the process of selecting electives in Zimbabwean high schools. Delegating a task of selecting electives for high school students who are in their adolescent stage creates a double barreled problem of managing their teenage hood as well as subject choices. On the other hand, teachers were seen to be going through a very rough patch during the selection period as it was mentioned to be full of stress and anxiety emanating from lack of feasible classes.

Basing on the conclusions of this study the following recommendations were made:

- There is need for the Zimbabwe government to revisit the grouping of subjects and selection policy for electives in high schools.

- School administrators should be guided by policy makers on how to implement the selection process for electives in order for high schools to operate following similar procedures.

- Funding for electives need to be greatly improved by sponsoring both the students who select the electives and also the subjects in terms of resources so that students may be attracted to study the electives.

\section{REFERENCES}

[1].Altunbay, M. (2018).The Effects of Elective Courses on the Personal Development of Prospective Teachers.Universal Journal of Educational Research 6(10): 2094-2100, http://www.hrpub.org DOI: 10.13189/ujer.2018.061006.

[2].Cohen, L., Manion, L. \& Morrison, K. (2011).Research Methods in Education.(7 ${ }^{\text {th }}$ Ed.).London: Routledge.

[3].Cram, L. \& Docampo, D. (2016). Academic performance and institutional resources: A cros country analysis of research universities. Research Gate.Https://www.researchgate.net/publication/307629243.

[4].Cresswell, J.W. (2012). Planning, conducting and evaluating qualitative research. Boston: Pearson.

[5]. Daly. C. \& Last, J. (2017). An analysis of free-choice electives in an undergraduate medical degree. BMC Medical Education Vol 17 113-120

[6].Denzin, N.K., \& Lincoln, Y.S. (2018).The landscape of qualitative research.(5th Ed.). Sage: Thousand Oaks, CA.

[7].Cubukcu, F. (2010) Student teacheres perceptions of teacher competence and their attributions for success and failure in learning.The Journal of International Social Research. Vol31, (10) 213-217.

[8].Futterman, L. (2016). Beyond the Classroom: Electives in school — essential or entertaining?lfutterman@ dadeschools.net.

[9].Gray, D.E. (2011). Doing Research in the Real World (2 $2^{\text {nd }}$ Ed.). London: SAGE Publications.

[10]. Guion, L.A., Diehl, D.C. \& McDonald, D. (2012). Conducting an in-depth interview.Department of Agriculture, cooperative extension service. Florida: IFAS.

[11]. Harirforoosh, S. \& Stewart, D.W. A.2016 descriptive investigation of the impact of student research projects arising from elective research courses. BMC Res Notes 9, 48 (2016).https://doi.org/10.1186/s13104-016-1865-1'

[12]. Kapungu, R.S. (2007). The Pursuit of Higher Education in Zimbabwe: A Futile Effort? A Paper Prepared for the Centre for International Private Enterprise (CIPE) International Essay Competition on „Educational Reform and Employment Opportunities ${ }^{\text {ee }}$

[13]. Manwa, L. (2019). Institutional Resources as a Predisposing Factor of Academic Attainments of Female University Students in Masvingo, Zimbabwe. International Journal of Research and Innovation in Social Science (IJRISS) |Volume III, Issue VI, June 2019|ISSN 24546186.

[14]. Manwa, L. Mahundi, P.\&Manwa, L. (2018). Perceptions of school administrators on the implementation of home economics subjects in Zimbabwean primary schools.Journal of Education and Practice, 9 (35) 60-65.

[15]. Marzano, R.J. (2009). Designing and teaching learning goals and objectives: Classroom strategies that work. Denver, CO: Marzano Research Laboratory.

[16]. Mavhunga, P. (2009). Africanising the curriculum: A case for Zimbabwe.Zimbabwe Journal of Educational Research 20:31-37.

[17]. Morse, J.M. \& Richards, L. (2013).Qualitative research design.Readme first for a user's guide to qualitative methods.(3rd Ed.). Los Angeles: Sage.

[18]. Movchan, L. \& Zarishniak, I. (2017). The role of elective courses in students' professional development: foreign experience. Comparative Professional Pedagogy 7(2) 20-26.

[19]. Organisation for Economic Co-operation and Development.(OECD). (2019). Creating Effective Teaching and Learning Environments: First Results from TALIS. EPEC. USA.

[20]. Salkind, N.J. (2017). Exploring research.(9th Ed.). Pearson Education: Upper Saddle River, NJ: Pearson Education. 
[21]. Samara, F. (2015). Factors Influencing Students' Choice of Elective Science Courses: A Case Study from the American University of Sharjah. Open Journal of Social Sciences, $3,9399$. http://dx.doi.org/10.4236/jss.2015.38010.

[22]. Saunders, M., Lewis, P., \& Thornhill, A. (2016).Research methods for business students.(7th Ed.). Essex, UK: Pearson Education.

[23]. Smith, K. (2018). Academic resource management.https://vtnews.vt.edu/articles/2018/09/kumarassociateviceprovost-academic-decision-support.html.

[24]. Soria, K M. Fransen, J \&Nackerud, S. (2017). The Impact of Academic Library Resources on Undergraduates ${ }^{\text {ee }}$ Degree Completion Soria Vol 78, (6).

[25]. Sweeney, K. (2012). Home Economics Practical coursework; Generating more effective Learning using Assessment for Learning principles.info@ccea.org.uk.

[26]. Ting, D. H. \& Lee C. K. C. (2012). Understanding students' choice of electives and its implications Journal of Studies in Higher Education Vol 37 (3), 309-325

[27]. Tope, O. (2012).Effects of Teachers' Competence on Academic Performance: A Case Study of Ikeja Local Government Area of Lagos State. Ego Books, Ogun State, Nigeria.EgoBooks.wwwometere.tk.

[28]. Wolpert-Gawron, H. (2018). The Case for Electives in Schools: Electives give students avenues for choice and can function as vehicles for core content standards.https://www.edutopia.org/profile/heather-wolpert-gawron

[29]. Yu, H. \&Mocan, N. (2018). The impact of high school curriculum on confidence, academic success, and mental and physical well-being of university students.Research in Higher Education Vol 42, pages 469-492. 